\title{
$\mathrm{BIM}$ 기반 사회기반 시설물 유지관리 도입을 위한 경제적 타당성 문석
}

김정환 $*$ 지승구 ${ }^{* *} \cdot$ 정태형*** · 서종원****

Kim, Jeonghwan*, Ji, Seung-gu**, Jeong, Taehyung ${ }^{\star * *}$, Seo, Jongwon ${ }^{\star * * *}$

\section{A Feasibility Study to Adopt BIM-based Infrastructure Management System}

\begin{abstract}
BIM (Building Information Modeling) is a new paradigm that includes construction life-cycle, and BIM has become mandatory regulation according to the Public Procurement Service since 2016, which accelerates its application. BIM is now expand from architectural field to infrastructure industry. Through pilot projects, BIM has been challenged with verification process. This trend has affected to maintenance and operation $(\mathrm{M} \& \mathrm{O})$ phase of construction life-cycle. Advanced country has already published their research and result with feasibility study and guidelines. In this paper, we conduct the feasibility study to adopt BIM-based infrastructure management system. Bridges and tunnels were selected as application target, and benefit/cost ratio were used. The result shows that BIM-based infrastructure management system is feasible when the level of detail is more than "Medium" in bridge, and "High" in tunnel.
\end{abstract}

Key words : BIM, Feasibility study, Facility management, Infrastructure

\section{초록}

$\mathrm{BIM}$ 은 건설 전단계를 포괄하는 새로운 패러다임으로서 2016년 조달청이 발주하는 정부기관 건축공사에서 BIM 설계를 전면 의무화 하는 등 $\mathrm{BIM}$ 기술의 도입이 점차 가속화 되고 있다. BIM 기술은 건축분야에서 벗어나 점차 사회기반시설물로 적용 범위가 확대되고 있으며 이미 국내 토목건설 공사 파일럿 프로젝트를 통해 적용 타당성이 검증되고 있다. 이러한 추세는 건설 생애주기에서 가장 넓은 범위를 차지하는 유지관리 단 계로까지 확장되고 있으며 선진국에서는 경제성 검토와 BIM기반 유지관리 가이드라인도 출간되고 있는 실정이다. 이에 본 연구에서는 사회기 반 시설물의 BIM기반 유지관리 기술 도입의 경제적 타당성 분석을 수행하였다. 교량과 터널을 적용 가능한 사회기반 시설물의 범위로 판단하였 고 편익/비용비(B/C ratio)를 활용하여 BIM 기술의 유지관리 도입의 경제적 타당성을 분석 하였다. BIM 모델의 세밀도별로 시나리오를 가정 하여 분석한 결과 편익/비용비는 교량의 경우 중간 이상의 세밀도에서, 터널은 높은 세밀도에서 1.00 이상의 값이 산출되어 시스템 도입의 경제 성이 있음을 확인할 수 있었다.

검색어 : BIM, 경제성 분석, 시설물 유지관리, 사회기반 시설물

\footnotetext{
* 정회원·한양대학교 건설환경공학과 박사과정 (kimjh0418@gmail.com)

** 정회원·한국시설안전공단 부장, 한양대학교 건설환경공학과 박사과정 (sgi@@kistec.or.kr)

*** 한양대학교 건설환경공학과 석사 (ancalagon04@gmail.com)

**** 정회원·교신저자·한양대학교 건설환경공학과 교수, P.E. (Corresponding Author·Hanyang University·jseo@hanyang.ac.kr)
}

Received June 26, 2013/ revised July 30, 2013/ accepted November 26, 2013 


\section{1. 서론}

\section{1 연구의 배경 및 필요성}

우리나라의 사회기반 시설물의 투자 추이는 점차 감소됨에 따라 현재 운용중인 시설물의 관리에 점차 관심이 증가되고 있다. 도로건 설부문의 경우 유지관리 투자액은 1999년 0.5조원에서 2007년 현재 1.0 조원으로 증가하여 신규투자액 대비 유지관리 비율은 9\% 에서 $15 \%$ 로 증가하였으며 이러한 추세는 구조물의 공용년수를 고려하면 향후 지속적으로 증가할 것이 분명하다. 특히 국내 교량의 경우 관리 대상의 사용연수를 고려해 보면 향후 10 년 이내에 급격한 유지관리비용의 상승을 초래할 수 있다(Jee and Seo, 2011).

현재 우리나라의 사회기반 시설물 유지관리는 시설물의 안전관 리에 관한 특별법에 의하여 한국시설안전공단의 FMS (시설물 정보관리 종합시스템)를 통하여 이루어지고 있다. FMS의 주요 기능은 1 종 및 2 종 시설물의 기본 및 상세제원 기록과 시설물의 정밀점검 및 정밀안전진단 시행 여부 관리, 유지관리 업무 수행 내용 관리 등이다.

시설물의 관리주체는 사회기반 시설물의 유지관리를 위하여 능 동적으로 FMS에 자료를 입력하고 이를 향후 유지관리를 위한 의사결정 기초자료로써 활용해야 하지만, 이를 적극적으로 활용하 고 있는 관리주체는 많지 않다. 또한 현재의 납품도서의 기준인 건설분야 도면정보 교환표준(KOSDIC)은 주로 TIFF 형식으로서, 여러 장의 이미지를 문서와 같이 조회할 수 있으나 단순한 이미지 파일로서 조회되기 때문에 유지관리에 필요한 속성정보는 포함하 고 있지 않아 유지관리단계에서의 정보활용성에 한계가 존재한다.

이러한 문제를 해결하기 위하여 BIM (Building Information Modeling)을 유지관리에 접목하여 설계-시공-유지관리로의 정보 체계화 및 운용성을 극대화하려고 노력하고 있다. BIM은 새로운 건설 패러다임으로 건설분야에서 각광을 받고 있으며, 서유럽 국가 건설 산업의 $36 \%$, 북미에서는 $49 \%$ 가 $\mathrm{BIM}$ 을 도입하여 사용하고 있을 정도이다(McGraw-Hill, 2012), 해외에서는 파일럿 프로젝트 를 통하여 유지관리 단계에서의 $\mathrm{BIM}$ 적용성을 검증하고, 이를 토대로 BIM기반 유지관리 가이드라인을 제안하고 있으며, 우리나 라는 설계-시공 단계에 $\mathrm{BIM}$ 기술을 적용한 일부 사례를 찾아볼 수 있으며(Infrastructure Design \& Management, 2010), 점차 확대적용 되려는 움직임을 보이고 있다. 향후 사회기반 시설물에 적용될 BIM 기술이 유지관리 단계에도 지속적으로 사용되기 위하 여 기술 도입의 경제적 타당성에 대하여 검토할 필요가 있다. 이에 본 연구에서는 BIM기반 유지관리 기술 도입을 위하여 사전에 기술 도입에 대한 경제적 타당성을 분석을 수행하여 기술 도입의 근거를 마련하고자 한다.

\section{2 연구의 방법 및 범위}

$\mathrm{BIM}$ 기반의 사회기반 시설물 유지관리 시스템 도입의 경제적 타당성을 평가함에 있어 사용될 수 있는 평가 도구는 대표적으로 편익/비용 분석(B/C Ratio)와 순현재가치분석(Net Present Value) 및 내부수익률(Internal Rate of Return) 등이 있다. 본 연구에서는 우리나라 정보화 사업에 대한 타당성 평가 시 사용될 수 있도록 한국개발연구원(KDI)에서 발간한 정보화부문 사업의 예비타당성 조사 표준지침 연구(KDI, 2004)에서 제안하는 프로세스에 따라 타당성을 평가하기로 하며, 사용되는 평가 도구는 편익/비용분석이 며, 기술의 타당성뿐만 아니라 사업성 평가와 정책 검토에도 사용되 는 가장 보편적인 분석 방법이다. 기술 적용 범위로는 1,2 종 시설물 중에서 가장 높은 비중을 차지하고 있는 교량과 터널에 대한 기술 적용 타당성을 검토하였다. 단, 논문 페이지 수의 제한으로 인하여 세부과정에서의 비용 및 편익 추정과 결과값은 수록하지 못하였으 며, 바용과 편익 항목과 산출에 필요한 근거 및 종합결과를 중심으로 경제적 타당성을 기술하였다.

\section{BIM기반 사회기반 시설물 유지관리의 경제적타당성 분석}

\section{1 분석 조건}

KDI (2004)에 따르면 정보화 사업의 편익 추정기간을 위해 다양한 사례들을 분석하여 정보시스템의 운용기간(생명기간)을 $5 \sim 10$ 년으로 탄력적으로 정하기를 권고하고 있다. 이러한 점들을 고려하여 'BIM기반 시설물 유지관리기술'의 생명기간을 시스템 개발 관계자들의 의견을 수렴하여 10 년으로 설정하였으며 본 시스 템을 개발하는 사업의 투자가 시작되는 시점을 2014년, 완료되는 시점을 2017년으로 가정하여 편익 추정 기간을 투자가 시작되는 다음 해인 2015년부터 2027년까지로 설정한다. 경제성 분석을 위한 사회적 할인율(Own Social Discount)는 KDI에서 제안하는 $5.5 \%$ 를 적용하기로 한다(KDI, 2004). 2012년 기준 불변가를 기준 으로, 매몰비용과 같이 이미 발생한 비용의 경우 할인율을 적용하여 2012년도 현재가로 환산하여 적용하기로 한다. 또한 모델의 세밀도 (Level of Detail, LoD)에 따라 유지관리단계에서의 활용 편차가 발생하므로 세밀도별로 비용 및 편익을 달리 산정하도록 하였다. 또한 앞서 연구의 범위에서 밝힌 바, 교량 및 터널을 대상으로 적용 타당성을 분석하였다.

\section{2 비용 분석}

$\mathrm{BIM}$ 기반 스마트 유지관리 시스템의 도입 당위성과 정량적인 경제적 파급 효과를 제시하기 위하여 비용 및 편익 분석은 반드시 수행되어야 한다. BIM기반 스마트 유지관리 시스템 도입을 위한 비용 항목은 다음과 같이 구분하고 각각을 추정한다. 


\subsection{1 데이터 구축}

본 논문에서의 데이터란 공용중인 시설물의 BIM 모델 구축에 소요되는 비용을 추정한다. 여기서 말하는 데이터베이스는 공용중 인 시설물의 BIM 모델을 뜻한다. 현재 거의 대부분의 사회기반 시설물은 BIM 모델이 존재하지 않아 유지관리를 위해 새로이 모델을 만들어야 한다. 이는 BIM기반 유지관리기술의 가장 핵심적 인 것으로 BIM 모델의 운용에 큰 비중을 차지하며 데이터베이스를 구성하는 핵심 요소도 BIM 모델이 될 것이기 때문이다.

시설물정보관리 종합시스템(FMS, Facility Management System) 내에서 관리중인 5 만여 개의 사회기반 시설물의 BIM 모델을 구축 하는데 소요되는 비용을 분석하면, BIM 모델의 표현수준별, 시설물 의 종류별로 BIM 모델링의 난이도와 시간 및 투입 인력 등이 결정되므로 다음과 같은 조건에 의하여 비용 추정을 수행하였다. 2011년에 결정된 2012년도 엔지니어링업체 표준임금(Ministry of Trade, Industry and Energy, 2011)과 투입인력을 고려하여 데이터 구축비용을 추정하였다.

\subsection{2 시스템 구축 및 응용프로그램 개발}

시스템 구축에 필요한 하드웨어과 시스템을 운영할 수 있는 응용프로그램의 개발은 BIM기반 유지관리 시스템의 도입을 위한 필수적인 비용항목이다. 하드웨어로는 BIM 구동을 위한 엔진과 데이터베이스 및 서버, 웹 서버, 백업을 위한 VTL (Virtual Tape Library) 등이 필요하다. 시스템 구축에 필요한 구성과 단가는 조달청 발주된 유사 용역 사례(데이터베이스 구축 사례)들에 대한 조사를 통하여 추정하였으며 최근 3년간의 자료를 조회하여 사용하 였다.

이러한 구성을 통해, 사용자(진단업체 등)는 터미널에서 단말기 를 통해 별도의 BIM 엔진 없이 웹상에서 응용프로그램만으로 본 시스템에 접근하여 사용할 수 있도록 하는데에 소요되는 비용을
산정하기로 하였다. BIM기반 스마트 유지관리 응용 프로그램 개발 비용은 단계별 원가와 소프트웨어 개발을 위한 기능점수, 보정계수 는 앞선 사례와 마찬가지로 조달청에서 발주된 소프트웨어 개발 발주 사례를 준용하여, 최근 3 년간 정부부처에서 사용하는 대단위 소프트웨어 개발 건수에 대한 조사와 검토를 통해 다음의 표와 같이 가정하기로 하였다.

\subsection{3 유지보수 및 관리}

데이터베이스 및 시스템 유지관리에 소요되는 비용은 하드소프 트웨어와 응용프로그램의 유지보수로 구분된다. 유지보수 및 관리 의 범위는 다음과 같다.

- 응용프로그램 실행 시 발생하는 오류나 에러 등을 보완

- 효율적인 사용을 목적으로 하는 변경보다 편리하게 사용할 수 있게 하기 위한 개선

- 수행법·제도에 따른 일부 업무변경, 사용자 요구사항 등에 따른 $\mathrm{S} / \mathrm{W}$ 기능 변경 및 성능 개선

- 주기별로 변동하는 자료의 원활한 처리를 위한 지원

- 응용프로그램의 유지보수 사항을 기록 및 보고

비용추정을 위하여 FMS의 기능 개선 및 유지 관리 용역의 비용 히스토리를 기반으로 사례 기반 추정(Case-Based Reasoning)을 수행하였다. 최근 5년간 공단에서 FMS의 성능 유지를 위해 투자된 예정금액을 바탕으로 유지보수 비용을 추정한다. 하드웨어의 유지 보수에는 매년 전산장비 유지보수와 5 년에 한번 컴퓨터 서버를 교체하는 비용이 소요되는 것으로 가정한다. 소프트웨어 유지보수 에는 2012년 유지보수 용역의 발주 금액을 참고하였으며 데이터베 이스 유지보수에는 데이터베이스 구축비용의 $0.5 \%$ 가 소요되는 것으로 가정하여 다음과 같이 비용을 추정하였다. 또한 용역 발주를 위해 투입되는 간접 비용 항목을 포함하였다. 계약과정과 심사 및 평가에 소요되는 인력 투입을 고려하였으며 이를 바탕으로 시스

Table 1. Total Cost for BIM Based Infrastructure Management System

\begin{tabular}{|c|c|c|c|c|c|}
\hline \multirow{2}{*}{\multicolumn{2}{|c|}{ Cost item }} & \multirow{2}{*}{ Item description } & \multicolumn{3}{|c|}{ Total (unit: Million Won) } \\
\hline & & & Low LoD & Midium LoD & High LoD \\
\hline \multicolumn{2}{|c|}{ BIM Data } & Data Making \& DB installation & 58,542 & 77,665 & 90,078 \\
\hline \multirow{2}{*}{ System } & $\mathrm{H} / \mathrm{W}$ & System development cost & 2,750 & 2,750 & 2,750 \\
\hline & $\mathrm{S} / \mathrm{W}$ & $\mathrm{S} / \mathrm{W}$ development cost & 1,381 & 1,381 & 1,381 \\
\hline \multirow{2}{*}{\multicolumn{2}{|c|}{ Maintenance \& Operation }} & Maintenance cost & 5,821 & 6,804 & 7,442 \\
\hline & & Labor cost for maintenance & 1,846 & 1,846 & 1,846 \\
\hline \multirow{4}{*}{\multicolumn{2}{|c|}{ Miscellaneous }} & Training center & 1,000 & 1,000 & 1,000 \\
\hline & & Sunk cost & 817 & 817 & 817 \\
\hline & & Salvage value & $-7,058$ & $-8,014$ & $-8,635$ \\
\hline & & Contingency & 6,268 & 8,179 & 9,421 \\
\hline \multicolumn{3}{|r|}{ Total } & 71,367 & 92,428 & 106,100 \\
\hline
\end{tabular}


템 및 데이터베이스 유지관리에 소요되는 인건비를 추정하였다.

\subsection{4 기타 비용}

기타 비용은 $\mathrm{DB}$ /시스템 구축 및 유지관리 비용에 포함되지 않는 비용 항목으로 매몰비용(기투자된 연구개발 예산)과 BIM 유지관리 기술 교육, 예비비, 서비스 종료 시점의 잔존가치로 나누어 평가하였으며 매몰비용의 경우 $5.5 \%$ 할인율로 현재가격으로 치환 하고, 기술 교육비용은 별도 계상없이 일괄적으로 계상하였으며, 예비비는 $10 \%$ 의 비율, 시스템의 잔존가치는 $100 \%$, 유지관리 데이 터의 잔존가치는 정액법(Straight line)을 적용하여 시스템 종료 시점에는 $5 \%$ 의 잔존가치를 포함하여 비용항목에서 제한하기로 가정하였다.

\subsection{5 비용 추정 결과}

이상에서 분석된 BIM기반 스마트 유지관리 시스템 도입에 소요 되는 비용을 종합하면 Table 1과 같이 나타낼 수 있다.

\section{3 편익 분석}

$\mathrm{BIM}$ 기술을 사회기반 시설물 유지관리에 적용함으로써 발생할 수 있는 편익은 크게 2가지로 볼 수 있다. 첫째는 업무 활용 편익으로, 시설물 안전점검 및 정밀안전진단 업무(이하 ‘점검진단업무')와 시설물 정밀점검 및 정밀안전진단 실시결과 평가 업무(이하 ‘점검진 단평가업무')에서 발생하는 편익이다. 둘째는 데이터 공동 활용 편익으로, 시설물에 대한 보수 및 보강(이하 '보수보강업무')과 교육 훈련 자료로 나눈다. 시설물 안전점검 및 정밀안전진단 업무는 대상 시설물의 사전조사 시 해당 시설물의 BIM에 연결되어 있는 과거 데이터를 바로 조회하여 분석 시간을 단축이 가능하며, 현장조 사 시 해당 시설물의 BIM에 조사 부위의 조사 내용(사진, 증상 등)을 현장에서 바로 기록하여 업무 처리 시간 단축 및 결과물의 품질 확보가 가능하다.

그 결과, 시설물의 보수 및 보강이 필요한 경우 본 시스템의 도입을 통해 구축될 BIM 데이터를 활용하여 보수 및 보강을 수행하 기 위한 설계 소요 시간 및 바용이 감소한다. 또한 시설물 정밀안전진 단 기술자 교육훈련 과정에 본 시스템의 도입을 통해 구축될 $\mathrm{BIM}$ 을 활용하여 교육훈련자의 원활한 이해를 통한 훈련 기간을 단축할 수 있다.

\subsection{1 편익 실현율}

데이터 활용에 의한 편익을 시스템 구축 다음 년도부터 바로 데이터를 공동으로 이용할 수 있으므로 구축 다음 년도부터 편익실 현율을 $100 \%$ 로 가정하며, 업무활용 편익의 경우, 비용이 투입되는 시점을 기준으로 5 년의 기간 동안 점진적으로 업무 활용을 위한 학습효과가 증진하여 6 년이 되는 해부터 $100 \%$ 실현되는 것으로 가정하였다. 이를 누적시킨 후 본 사업의 투입 예산의 비율을 2014 년 15.4\%, 2015년 26.9\%, 2016년 23.1\%, 2017년 34.6\%으로 가정하고 이를 합산하여 계상하면 연도별 편익 실현율율 구할 수 있고 그 결과는 Table 2 와 같다.

\subsection{2 업무 활용에 따른 편익}

\section{가. 시설물 안전점검 및 정밀안전진단 업무 활용 편익}

점검진단업무는 시특법에 따라 수행 중이며, 사회기반시설물의 유지관리 관련 업무 중 가장 주된 업무이다. 점검진단 업무는 크게 정기점검, 정밀점검, 긴급점검, 정밀안전진단으로 나눌 수 있으며, 각 시설물별로 그 건수와 비용이 집계된 통계자료를 $\mathrm{FMS}$ 에서 찾을 수 있다. 추정값을 산정하기 위하여 최근 5년간의 통계자료를 확보하였다(FMS, 2012). FMS의 통계정보안전 및 유지관리현황 $>$ 점검진단계획/실적 > 시설물별 점검진단실시현황) 다만 $\mathrm{FMS}$ 의 점검진단자료의 무결성이 확보되지 않아 신뢰할 수 없는 데이터가 검색 결과에 포함되는 바, 본 연구에서는 특이값(outlayer)은 모두 제외하여 연간투입비용을 산출하였다.

편익발생율은 전문가 38 인의 설문조사에 의하여 진행되었으며, 설문은 2012년 7월과 8월 사이에 이루어졌으며 인터넷 설문을 통해 의견을 집계하였다. 설문자는 정부산하단체 $(61.5 \%)$, 안전진 단전문기관(19.2\%), 유지관리업체(15.4\%), 지방자치단체(3.8\%) 의 비율이며, 대부분 교량터널(47.7\%)을 전문 분야로 삼고 있다. 설문인단은 진단(32.4\%)과 관리(26.5\%)를 전문으로 하고 있어 전문성을 충분히 갖추었으며 편익 발생율은 모두 상기설문조사를 통해 산정되었다. 높은 수준의 BIM 세밀도를 적용하였을 경우에 정기점검은 $7 \%$, 정밀점검 및 긴급점검은 $7 \%$, 정밀안전진단은 $5 \%$ 를 적용하였다. 중간 수준의 세밀도는 위의 값에 $1 / 2$ 를, 낮은 수준의 세밀도는 $1 / 4$ 를 적용하였다. Eq. (1)에 따라 편익 추정 결과를 계산하였으며 그 결과는 2.3.4절의 Tables 5 and 6 에 수록되 어있다.

Table 2. Realization Rate of Benefit

\begin{tabular}{c|c|c|c|c|c|c|c|c|c|c|c|c|c|c}
\hline \hline Year & $' 14$ & $\prime 15$ & $\prime 16$ & $\prime 17$ & $\prime 18$ & $\prime 19$ & $' 20$ & $' 21$ & $' 22$ & $' 23$ & $' 24$ & $' 25$ & $' 26$ & $' 27$ \\
\hline $\begin{array}{c}\text { Realization rate for work } \\
\text { application \%) }\end{array}$ & 0 & 3 & 12 & 25 & 45 & 65 & 82 & 93 & 100 & 100 & 100 & 100 & 100 & 100 \\
\hline $\begin{array}{c}\text { Realization rate for data } \\
\text { application (\%) }\end{array}$ & 0 & 15 & 42 & 65 & 100 & 100 & 100 & 100 & 100 & 100 & 100 & 100 & 100 & 100 \\
\hline
\end{tabular}


연간 절감 예상액 $=$ 점검진단 건당 소요비용 * 연평균 점검진단 건수 * 점검진단 편익발생율 * 시설물별 보정계수

\section{나. 시설물 정밀점검 및 정밀안전진단 실시결과 평가 업무에 따른 편익}

정밀점검 및 정밀안전진단의 결과평가업무를 수행하기 위해 점검진단 결과자료를 사전검토 후 평가대상을 선정하여 결과물을 평가하게 되는데, 본 BIM기반 스마트 유지관리기술을 도입하면 관련된 기준 또는 과거이력을 찾기 위해 불필요하게 소요되는 시간 없이 모델링에서 바로 조회할 수 있어 결과평가업무 소요시간 을 단축할 수 있다. 평가업무에서 기대할 수 있는 편익 추정은 Table 3의 추정치와 다음의 식에 의하여 계산될 수 있으며 세밀도별 편익발생율은 앞서 업무활용편익에서의 추정과 동일하다. 이를 토대로 얻어진 편익은 2.3.4절의 Tables 5 and 6에 수록되어 있다.

연간 절감 예상액 $=($ 결과사전검토 연평균 건수 * 사전검토 편익발생율 + 결과평가 연평균 건수 * 결과평가 편익발생율) $*$ 위원회 위원 보수 * 결과평가 건당 평균 소요 시간 $=(293$ 건/ 년 * 30\% + 47건/년 * 10\%) * 23,000원/ 시간 * 24 시간/건 $=51$ 백만원/년

\subsection{3 데이터 활용 편익}

\section{가. 시설물의 보수 및 보강을 위한 데이터 활용 편의}

보수보강업무는 손상 구조물의 영향정도, 구조물의 중요도, 사용
환경조건 및 경제성 등에 의해서 보수 및 보강 방법 및 수준을 정하여 실시한다. BIM기반 스마트 유지관리기술을 도입하게 되면 대상 시설물의 BIM에 링크된 상태평가 또는 안전성평가 결과를 바로 확인할 수 있어 보수 및 보강을 수행하기 위한 사전조사, 세부시공계획 등 설계단계에서 소요되는 시간을 단축할 수 있다. 보수보강을 위한 데이터 활용에 따른 시간 비용 절감액을 추정하 기 위한 구성요소, 추정근거값을 위하여 최근 5 년간의 $\mathrm{FMS}$ 의 “현황 및 통계 > 통계정보 > 안전 및 유지관리현황 > 보수보강계획/ 실적 >보수보강실적현황"을 활용하였다. 본 데이터 또한 신뢰할 수 없는 데이터가 다수 존재하였으며, 이에 대한 필터링 및 보정작업 을 거친 후 분석에 적용하였다. 데이터 활용에 대한 편익은 $\mathrm{Eq}$. (3)을 통해 계산될 수 있다.

연간 절감 예상액 $=$ 보수보강 일평균 소요비용 * 보수보강 건평균 소요일수 * 보수보강 연평균 건수 * 보수보강 편익발생율 * 시설물별 보정 계수

편익 발생율은 높은 수준의 세밀도를 적용하였을 경우에 보수, 보강은 $3.0 \%$, 개량, 증설 등의 기타 항목은 $1.0 \%$ 를 적용하였다. 중간 수준의 세밀도는 위의 값에 $1 / 2$ 를, 낮은 수준의 세밀도는 $1 / 4$ 를 적용하였다. 이를 표로 나타내면 2.3.4절의 Tables 5 and 6 과 같다.

\section{나. 교육 훈련을 위한 데이터 활용 편익}

교육 훈련은 법에 의한 시설물의 안전점검 또는 정밀안전진단

Table 3. Estimation of Benefit of Safety Inspection and Evaluation Work

\begin{tabular}{|c|c|c|}
\hline \multicolumn{2}{|c|}{ Factor } & Value \\
\hline \multicolumn{2}{|c|}{ Pre-evaluation cases } & 293 case/year \\
\hline \multicolumn{2}{|c|}{ Safety inspection cases } & 47 case/year \\
\hline \multicolumn{2}{|c|}{ Payment per cases } & $23,000 \mathrm{Won} /$ case \\
\hline \multicolumn{2}{|c|}{ Evaluation time per cases } & 24 hour/case \\
\hline \multirow{2}{*}{ Realization rate for benefit } & Pre-evaluation & $30 \%$ \\
\hline & Result evaluation & $10 \%$ \\
\hline
\end{tabular}

Table 4. Estimation of Benefit for Education Training

\begin{tabular}{c|c|l}
\hline \hline Factor & Value & Considering \\
\hline Education Training Fee & $435,000 \mathrm{Won} / \mathrm{hr}$ & - Average tuition fee considering education fee and the number of trainee \\
\hline Education Training hour & 65 hour $/ \mathrm{case}$ & - Average tuition hour per case \\
\hline Average training case & $20 \mathrm{cases} / \mathrm{yr}$ & - Education training data from KISTEC \\
\hline Realization rate for training & $10 \%$ & $\begin{array}{l}\text { Enhancing the trainee's understanding for providing BIM data with safety } \\
\text { inspection instruction and evaluation so that improve training efficiency }\end{array}$ \\
\hline
\end{tabular}


업무를 수행하고자 하는 사람이 해당분야의 교육과정을 이수하여 야 하는 법정교육을 말한다. 이는 정밀안전진단 기술자 과정과 주택관리사 안전점검과정으로 나뉘며, 각각 10 일(73시간), 5 일(35 시간) 동안 교육 훈련을 실시하고 있다. 교육 훈련을 위한 데이터 활용에 따른 시간 비용 절감액을 추정하기 위한 구성요소, 추정근거 및 추정값은 Table 4 와 같다. 이를 근거로 편익 추정 결과는 Eq. (4)에 의하여 계산될 수 있다.
연간 절감 예상액 $=$ 교육훈련 시간평균 강의비용 * 교육훈련 건당 강의시간 * 교육훈련 연평균 건수 * 교육훈련 편익발생율 $=435,000$ 원/시간 * 65시간건 * 20 건년 * $10 \%=57$ 백만원년

다른 업무들과 달리 교육훈련업무를 수행하는 데에 있어서 세밀 도에 따른 편익의 차이가 발생하지 않을 것이므로 세밀도에 따른

Table 5. Benefit for Work Application

\begin{tabular}{|c|c|c|c|c|c|c|}
\hline \multirow{3}{*}{ Year } & \multicolumn{6}{|c|}{ Benefit for work application (Unit: Million Won) } \\
\hline & \multicolumn{3}{|c|}{ Safety inspection } & \multicolumn{3}{|c|}{ Evaluation } \\
\hline & Low LoD & Medium LoD & High LoD & Low LoD & Medium LoD & High LoD \\
\hline 2015 & 144 & 287 & 575 & 1 & 1 & 2 \\
\hline 2016 & 539 & 1,077 & 2,154 & 4 & 5 & 6 \\
\hline 2017 & 1,149 & 2,298 & 4,596 & 9 & 11 & 13 \\
\hline 2018 & 2,083 & 4,165 & 8,331 & 17 & 21 & 23 \\
\hline 2019 & 3,016 & 6,032 & 12,065 & 25 & 30 & 33 \\
\hline 2020 & 3,806 & 7,612 & 15,225 & 31 & 37 & 42 \\
\hline 2021 & 4,345 & 8,690 & 17,379 & 36 & 43 & 48 \\
\hline 2022 & 4,668 & 9,336 & 18,672 & 38 & 46 & 51 \\
\hline 2023 & 4,668 & 9,336 & 18,672 & 38 & 46 & 51 \\
\hline 2024 & 4,668 & 9,336 & 18,672 & 38 & 46 & 51 \\
\hline 2025 & 4,668 & 9,336 & 18,672 & 38 & 46 & 51 \\
\hline 2026 & 4,668 & 9,336 & 18,672 & 38 & 46 & 51 \\
\hline 2027 & 4,668 & 9,336 & 18,672 & 38 & 46 & 51 \\
\hline Total & 43,089 & 86,179 & 172,357 & 354 & 424 & 472 \\
\hline
\end{tabular}

Table 6. Benefit for Data Application and Total Amount

\begin{tabular}{|c|c|c|c|c|c|c|c|}
\hline \multirow{3}{*}{ Year } & \multicolumn{4}{|c|}{ Benefit for data application (Unit: Million Won) } & \multirow{2}{*}{\multicolumn{3}{|c|}{ Total }} \\
\hline & \multicolumn{3}{|c|}{ Repair and reinforcement } & \multirow{2}{*}{$\begin{array}{c}\text { Education } \\
\text { training }\end{array}$} & & & \\
\hline & Low LoD & Medium LoD & High LoD & & Low LoD & Medium LoD & High LoD \\
\hline 2015 & 321 & 642 & 1,677 & 8 & 474 & 939 & 2,261 \\
\hline 2016 & 899 & 1,797 & 4,695 & 24 & 1,466 & 2,904 & 6,879 \\
\hline 2017 & 1,391 & 2,782 & 7,266 & 37 & 2,586 & 5,128 & 11,911 \\
\hline 2018 & 2,140 & 4,280 & 11,178 & 57 & 4,296 & 8,522 & 19,588 \\
\hline 2019 & 2,140 & 4,280 & 11,178 & 57 & 5,237 & 10,398 & 23,333 \\
\hline 2020 & 2,140 & 4,280 & 11,178 & 57 & 6,034 & 11,986 & 26,501 \\
\hline 2021 & 2,140 & 4,280 & 11,178 & 57 & 6,577 & 13,069 & 28,662 \\
\hline 2022 & 2,140 & 4,280 & 11,178 & 57 & 6,903 & 13,718 & 29,958 \\
\hline 2023 & 2,140 & 4,280 & 11,178 & 57 & 6,903 & 13,718 & 29,958 \\
\hline 2024 & 2,140 & 4,280 & 11,178 & 57 & 6,903 & 13,718 & 29,958 \\
\hline 2025 & 2,140 & 4,280 & 11,178 & 57 & 6,903 & 13,718 & 29,958 \\
\hline 2026 & 2,140 & 4,280 & 11,178 & 57 & 6,903 & 13,718 & 29,958 \\
\hline 2027 & 2,140 & 4,280 & 11,178 & 57 & 6,903 & 13,718 & 29,958 \\
\hline Total & 24,009 & 48,019 & 125,420 & 634 & 68,087 & 135,256 & 298,883 \\
\hline
\end{tabular}


편익발생율에 차등을 두지 아니하였다. 교육훈련업무의 연간절감 예상액은 약 5,700 만원이 발생할 것으로 예상된다.

\subsection{4 편익 추정 결과}

지금까지 살펴본 결과를 종합하였을 때, 2015년부터 2027년까 지의 기간 동안 BIM기반 스마트 유지관리기술이 도입으로 발생하 는 편익의 총액은 높은 수준의 세밀도를 적용할 경우에 약 3,000 억 원으로, 중간 수준의 세밀도를 적용할 경우에 약 1,350 억원으로, 낮은 수준의 세밀도를 적용할 경우에 약 680 억원으로 추정한다.

\section{4 종합 분석}

2.2절과 2.3절에서 비용과 편익을 정량적으로 도출하였다. 이를 근거로 교량과 터널에 $\mathrm{BIM}$ 기반 유지관리 시스템을 적용하였을 경우에 대하여 각각의 $\mathrm{B} / \mathrm{C}$ ratio를 구하였다. Table 7은 교량(B), 터널(T)로 구분된 투입 비용이고, Table 8 은 비용항목에 대한 정량적 분석 결과이다.

Table 9는 교량 및 터널에 관한 세밀도별 $\mathrm{B} / \mathrm{C}$ ratio이다. 교량 유지관리에 $\mathrm{BIM}$ 을 적용하는 것이 전반적으로 터널보다 효과가 다소 높은 것으로 분석되었다. 교량은 중간 이상의 세밀도를 가진

Table 7. Total Cost (B-Bridge and T-Tunnel)

\begin{tabular}{|c|c|c|c|c|c|c|c|c|}
\hline \multirow{3}{*}{\multicolumn{2}{|c|}{ Cost item }} & \multirow{3}{*}{ Item description } & \multicolumn{6}{|c|}{ Total (Unit: Million Won) } \\
\hline & & & \multicolumn{2}{|c|}{ Low LoD } & \multicolumn{2}{|c|}{ Medium LoD } & \multicolumn{2}{|c|}{ High LoD } \\
\hline & & & $\mathrm{B}$ & $\mathrm{T}$ & B & $\mathrm{T}$ & $\mathrm{B}$ & $\mathrm{T}$ \\
\hline \multicolumn{2}{|c|}{ BIM Data } & Data Making \& DB installation & 47,975 & 10,567 & 63,646 & 14,019 & 73,819 & 16,260 \\
\hline \multirow{2}{*}{ System } & $\mathrm{H} / \mathrm{W}$ & System development cost & 2,750 & 2,750 & 2,750 & 2,750 & 2,750 & 2,750 \\
\hline & $\mathrm{S} / \mathrm{W}$ & $\mathrm{S} / \mathrm{W}$ development cost & 1,381 & 1,381 & 1,381 & 1,381 & 1,381 & 1,381 \\
\hline \multirow{2}{*}{\multicolumn{2}{|c|}{$\begin{array}{c}\text { Maintenance \& } \\
\text { Operation }\end{array}$}} & Maintenance cost & 9,050 & 9,050 & 11,087 & 11,087 & 12,409 & 12,409 \\
\hline & & Labor cost for maintenance & 1,846 & 1,846 & 1,846 & 1,846 & 1,846 & 1,846 \\
\hline \multirow{4}{*}{\multicolumn{2}{|c|}{ Miscellaneous }} & Training center & 950 & 950 & 950 & 950 & 950 & 950 \\
\hline & & Sunk cost & 817 & 817 & 817 & 817 & 817 & 817 \\
\hline & & Salvage value & $-6,529$ & $-4,659$ & $-7,313$ & $-4,832$ & $-7,822$ & $-4,944$ \\
\hline & & Contingency & 5,211 & 1,470 & 6,778 & 1,815 & 7,795 & 2,039 \\
\hline \multicolumn{3}{|r|}{ Total } & 63,450 & 24,172 & 81,942 & 29,833 & 93,946 & 33,508 \\
\hline
\end{tabular}

Table 8. Total Benefit (B-Bridge and T-Tunnel)

\begin{tabular}{|c|c|c|c|c|c|c|c|c|c|c|c|c|c|c|}
\hline \multirow{3}{*}{ Year } & \multicolumn{4}{|c|}{ Benefit for work application } & \multicolumn{4}{|c|}{ Benefit for data application } & \multicolumn{6}{|c|}{ Total (Unit: Million Won) } \\
\hline & \multicolumn{2}{|c|}{ Safety inspection } & \multicolumn{2}{|c|}{ Evaluation } & \multicolumn{2}{|c|}{$\begin{array}{l}\text { Repair and } \\
\text { reinforcement }\end{array}$} & \multicolumn{2}{|c|}{$\begin{array}{c}\text { Education } \\
\text { training }\end{array}$} & \multicolumn{2}{|c|}{ Low LoD } & \multicolumn{2}{|c|}{ Medium LoD } & \multicolumn{2}{|c|}{ High LoD } \\
\hline & B & $\mathrm{T}$ & $\mathrm{B}$ & $\mathrm{T}$ & $\mathrm{B}$ & $\mathrm{T}$ & $\mathrm{B}$ & $\mathrm{T}$ & $\mathrm{B}$ & $\mathrm{T}$ & $\mathrm{B}$ & $\mathrm{T}$ & B & $\mathrm{T}$ \\
\hline 2015 & 493 & 81 & 2 & 2 & 1,084 & 200 & 8 & 8 & 404 & 80 & 799 & 150 & 1,587 & 291 \\
\hline 2016 & 1,850 & 305 & 6 & 6 & 3,036 & 559 & 24 & 24 & 1,250 & 244 & 2,472 & 461 & 4,915 & 894 \\
\hline 2017 & 3,947 & 650 & 13 & 13 & 4,698 & 866 & 37 & 37 & 2,207 & 425 & 4,370 & 806 & 8,694 & 1,565 \\
\hline 2018 & 7,153 & 1,178 & 23 & 23 & 7,227 & 1,332 & 57 & 57 & 3,669 & 701 & 7,267 & 1,332 & 14,460 & 2,589 \\
\hline 2019 & 10,360 & 1,705 & 33 & 33 & 7,227 & 1,332 & 57 & 57 & 4,478 & 841 & 8,880 & 1,605 & 17,677 & 3,127 \\
\hline 2020 & 13,073 & 2,152 & 42 & 42 & 7,227 & 1,332 & 57 & 57 & 5,163 & 959 & 10,244 & 1,836 & 20,399 & 3,582 \\
\hline 2021 & 14,923 & 2,457 & 48 & 48 & 7,227 & 1,332 & 57 & 57 & 5,630 & 1,039 & 11,174 & 1,994 & 22,254 & 3,893 \\
\hline 2022 & 16,033 & 2,639 & 51 & 51 & 7,227 & 1,332 & 57 & 57 & 5,910 & 1,088 & 11,733 & 2,088 & 23,368 & 4,079 \\
\hline 2023 & 16,033 & 2,639 & 51 & 51 & 7,227 & 1,332 & 57 & 57 & 5,910 & 1,088 & 11,733 & 2,088 & 23,368 & 4,079 \\
\hline 2024 & 16,033 & 2,639 & 51 & 51 & 7,227 & 1,332 & 57 & 57 & 5,910 & 1,088 & 11,733 & 2,088 & 23,368 & 4,079 \\
\hline 2025 & 16,033 & 2,639 & 51 & 51 & 7,227 & 1,332 & 57 & 57 & 5,910 & 1,088 & 11,733 & 2,088 & 23,368 & 4,079 \\
\hline 2026 & 16,033 & 2,639 & 51 & 51 & 7,227 & 1,332 & 57 & 57 & 5,910 & 1,088 & 11,733 & 2,088 & 23,368 & 4,079 \\
\hline 2027 & 16,033 & 2,639 & 51 & 51 & 7,227 & 1,332 & 57 & 57 & 5,910 & 1,088 & 11,733 & 2,088 & 23,368 & 4,079 \\
\hline 계 & 147,995 & 24,362 & 472 & 472 & 81,092 & 14,945 & 634 & 634 & 58,260 & 10,817 & 115,602 & 0 & 230,193 & 40,414 \\
\hline
\end{tabular}


Table 9. Result of Benefit/Cost Ratio

\begin{tabular}{c|c|r|r|r}
\hline \hline \multicolumn{2}{c|}{ Case } & \multicolumn{1}{c|}{ Cost } & \multicolumn{1}{c|}{ Benefit } & B/C \\
\hline \multirow{4}{*}{ Bridge } & Low LoD & 63,450 & 58,260 & 0.92 \\
\cline { 2 - 5 } & Medium LoD & 81,942 & 115,602 & 1.41 \\
\cline { 2 - 5 } & High LoD & 93,946 & 230,193 & 2.45 \\
\hline \multirow{4}{*}{ Tunnel } & Low LoD & 24,172 & 10,817 & 0.45 \\
\cline { 2 - 5 } & Medium LoD & 29,833 & 20,712 & 0.69 \\
\cline { 2 - 5 } & High LoD & 33,508 & 40,414 & 1.21 \\
\hline
\end{tabular}

$\mathrm{BIM}$ 모델을 이용하는 경우에 편익이 비용보다 높아지고, 터널은 높은 세밀도의 BIM 모델을 이용해야 수익성이 있는 것으로 분석 되었다.

\section{3. 결론}

본 연구에서는 다양한 BIM 모델의 세밀도별, 그리고 대표적인 사회기반 시설물인 교량과 터널을 대상으로 비용-편익 분석을 수행 하였다. 분석 결과 교량은 중간 이상의 세밀도에서, 터널은 높은 수준의 세밀도에서 1 이상으로 분석되었다. 이는 어느 정도 높은 데이터 세밀도를 갖는 BIM 데이터를 기반으로 유지관리 시스템을 운영해야 투자 가치가 있음을 반증하는 것으로서, 활용도가 낮은 $\mathrm{BIM}$ 데이터로는 실익을 얻기 어려울 것으로 전망하는 분석 결과이다.

주된 이유로는 시스템 개발 비용과 같이 적용 범위에 상관없이 기술 도입을 위해 고정적으로 투자되는 금액이 존재하게 되는데, 이러한 고정 비용이 데이터의 세밀도와는 관계없이 반드시 투자되 어야 하기 때문이다. 또한 시스템 개발의 효용가치를 극대화하기 위해서는 일부 사회기반 시설물에 BIM기반 유지관리 기술을 적용
하는 것 보다는 폭넓은 기술 적용이 유리한 것으로 볼 수 있다. 따라서 다양한 시설물에 활용될 수 있도록 추진전략을 제시하는 것이 중요할 것이다.

$\mathrm{BIM}$ 기술은 향후 건설부문 유지관리의 새로운 대안으로 자리매 김할 것이며 예측하는 것보다 빠른 기술 전개가 이루어 질 것으로 판단된다. 선진국의 $\mathrm{BIM}$ 인식과 활용에 관한 통계를 보면 알 수 있듯이, 이미 BIM 기술 도입에 대한 다차원적 대응이 이루어지고 있다.

또한 해외 건설공사가 주력 비즈니스 모델로 전환되고 있는 시점에서 새로운 유지관리 기술 개발 및 기술력 확보를 통한 가치창 출을 유도할 수 있도록 해야 한다. 더욱이 현재 소프트웨어와 요소기 술들의 개발이 활발히 진행되고 있어 기술력 확보에 대한 우려는 없으며 운용과 관리적 측면의 노하우가 축적되면 충분한 기술적 타당성이 있을 것으로 판단된다.

\section{References}

Infrastructure Design \& Management (2010). "BIM case study in infrastructure." Proceeding of 2010 Annual Conference \& Civil Expo (in Korean).

Jee, S. G. and Seo, J. W. (2011). "Development of network level management system of road facilities based on the asset management concept." Journal of the Korea Institute for Structural Maintenance and Inspection, Vol. 15, No. 4, pp. 146-154 (in Korean).

KDI (2004). Standard guideline of feasibility test for informatics Project (in Korean).

McGraw-Hill Construction (2012). Smart market report: The business value of BIM for infrastructure, McGraw-Hill Construction.

Ministry of Trade, Industry and Energy (2011). Standard wage for engineering work (in Korean). 